\title{
Lifestyle behaviors among 4,343 Brazilian adults with severe mental illness and 55,859 general population controls: data from the Brazilian National Health Survey
}

\author{
André O. Werneck, ${ }^{1}$ iD Davy Vancampfort, ${ }^{2}$ Adewale L. Oyeyemi, ${ }^{3}$ Célia L. Szwarcwald, ${ }^{4}$ \\ Brendon Stubbs, ${ }^{5,6}$ Danilo R. Silva ${ }^{7}$
}

\begin{abstract}
${ }^{1}$ Departamento de Educação Física, Universidade Estadual Paulista Júlio de Mesquita Filho (UNESP), Presidente Prudente, SP, Brazil.
${ }^{2}$ Department of Rehabilitation Sciences, KU Leuven, University of Leuven, Leuven, Belgium. ${ }^{3}$ Department of Physiotherapy, College of Medical Sciences, University of Maiduguri, Borno State, Nigeria. ${ }^{4}$ Instituto de Comunicação e Informação Científica e Tecnológica em Saúde (ICICT), Fundação Oswaldo Cruz (Fiocruz), Rio de Janeiro, RJ, Brazil. ${ }^{5}$ Department of Psychological Medicine, Institute of Psychiatry, Psychology and Neuroscience, King's College London, London, United Kingdom. ${ }^{6}$ South London and Maudsley NHS Foundation Trust, London, United Kingdom. ${ }^{7}$ Departamento de Educação Física, Universidade Federal de Sergipe (UFS), São Cristóvão, SE, Brazil.
\end{abstract}

\begin{abstract}
Objective: To analyze the association between severe mental illnesses and health behaviors among Brazilian adults.

Methods: We used data from the Brazilian National Health Survey, a large nationally representative cross-sectional study conducted in 2013 among 60,202 adults ( $\geqslant 18$ years). Clinical diagnoses (major depressive disorder, bipolar disorder and schizophrenia), lifestyle behaviors (leisure-time physical activity, TV viewing, tobacco use and the consumption of alcohol, sweets, and soft drinks) and potential confounders (chronological age, race, educational and employment status) were selfreported. Logistic regression models were used to examine the associations between severe mental illness and lifestyle behaviors, adjusting for confounders.

Results: Schizophrenia $(n=41)$ was associated with lower odds of physical activity $(O R 0.08[95 \% \mathrm{Cl}$ $0.01-0.58])$. Major depressive disorder $(n=4,014)$ was associated with higher odds of TV viewing (OR 1.34 [95\% Cl 1.12-1.61]), tobacco use (OR $1.37(95 \% \mathrm{Cl} 1.18-1.58]$ ), consumption of sweets (OR $1.34(95 \% \mathrm{Cl} 1.15-1.55])$ and consumption of soft drinks (OR $1.24(95 \% \mathrm{Cl} 1.06-1.45])$. There were no significant associations between bipolar disorder $(n=47)$ and any lifestyle behaviors.

Conclusions: Schizophrenia was associated with lower physical activity, while major depressive disorder was associated with increased TV viewing, tobacco use, and consumption of sweets and soft drinks. These findings reinforce the need for prevention and treatment interventions that focus on people with severe mental illness in Brazil.
\end{abstract}

Keywords: Physical activity; sedentary behavior; smoking; depression; schizophrenia

\section{Introduction}

People with severe mental illness (SMI), including major depressive disorder, bipolar disorder and schizophrenia, are at risk for cardiovascular diseases and associated reductions in life expectancy. ${ }^{1,2}$ People with SMI also have a high burden of disability-adjusted life years. ${ }^{3}$ Beyond the biological mechanisms underlying the association between $\mathrm{SMI}$ and cardiovascular diseases, ${ }^{4}$ unhealthy lifestyle behaviors, including psychotropic medication use, physical inactivity, sedentary behavior and poor dietary patterns, play an important role. ${ }^{5-7}$

Understanding the lifestyle behaviors specific to certain SMls could help identify behavioral factors relevant for screening at risk sub-groups in need of intensive care.

Correspondence: André O. Werneck, Departamento de Educação Física, Universidade Estadual Paulista Júlio de Mesquita Filho (UNESP), Rua Roberto Símonsen, 305, CEP 19060-900, Presidente Prudente, SP, Brazil.

E-mail: andreowerneck@gmail.com

Submitted Jul 23 2019, accepted Sep 02 2019, Epub Dec 202019.
Recently, a Lancet commission was launched to summarize evidence of lifestyle behaviors as well as to stimulate the promotion of healthy behaviors among people with mental illness, providing a health system framework for the prevention and treatment of mental illness. ${ }^{8}$

Previous studies have found that SMI is associated with different lifestyle behaviors, such as lower physical activity, ${ }^{7}$ higher sedentary behavior, ${ }^{7}$ unhealthy diet, ${ }^{6,9}$ alcohol consumption ${ }^{8}$ and tobacco use. ${ }^{10}$ However, these studies were mainly conducted in high income-countries ${ }^{8}$; few studies have investigated the association between lifestyle behaviors and SMI in low- and middle-income countries. Since it is expected that countries of different income levels would have different levels and patterns of poverty and, consequently, different disease and behavior

How to cite this article: Werneck $A O$, Vancampfort $D$, Oyeyemi $A L$, Szwarcwald CL, Stubbs B, Silva DR. Lifestyle behaviors among 4,343 Brazilian adults with severe mental illness and 55,859 general population controls: data from the Brazilian National Health Survey. Braz J Psychiatry. 2020;42:245-249. http://dx.doi.org/10.1590/15164446-2019-0621 
patterns, ${ }^{11,12}$ it is important to produce country-specific evidence. Therefore, in a nationally representative Brazilian sample that compared adults with SMls and adults from the general population, our aim was to analyze the association between SMI and lifestyle behaviors.

\section{Methods}

\section{Sample}

Data collected from the Brazilian National Health Survey ${ }^{13}$ were used. The survey was a cross-sectional epidemiological study, conducted during 2013 with a nationally representative sample of adults (18 to 100 years old). The sampling process involved several stages: first, census tracts were randomly selected; next, households were randomly selected; and finally, within the households, one adult was randomly selected. The minimum sample size per federal unit (i.e. state) $(n=27)$ was 1,800 households, with a total of 64,348 households. For this investigation, the sample consisted of 60,202 adults with complete data for all variables, which were divided into general population controls $(n=55,859)$, major depressive disorder $(n=4,014)$, bipolar disorder $(n=47)$, schizophrenia $(n=41)$ and mental multimorbidity $(n=241)$. Sampling weights were created based on household size, adjusting for non-response by sex and total population by sex and age. All analyses considered sampling weights. Further details of the sampling and weighting process have been previously published. ${ }^{13}$ All variables were collected through household interviews.

\section{Severe mental illness}

The presence of SMI (i.e., major depressive disorder, bipolar disorder or schizophrenia) was evaluated through questions about lifetime diagnosis by a physician. The response options were either yes or no. Besides reporting data for separate diagnoses, we also analyzed the risks in individuals with more than one SMls; this group was classified as the mental multimorbidity subgroup.

\section{Lifestyle behaviors}

TV viewing was estimated through the question: "How many hours a day you usually spend watching TV?" The responses options were: a) Less than $1 \mathrm{~h}$; b) More than $1 \mathrm{~h}$, but less than $2 \mathrm{~h}$; c) More than $2 \mathrm{~h}$, but less than $3 \mathrm{~h}$; d) More than $3 \mathrm{~h}$, but less than $4 \mathrm{~h}$; e) More than $4 \mathrm{~h}$, but less than $5 \mathrm{~h}$; f) More than $5 \mathrm{~h}$, but less than $6 \mathrm{~h} ; \mathrm{g}$ ) More than $6 \mathrm{~h}$; and $\mathrm{h}$ ) I do not watch TV. We selected a cut-off point of 5 hours/day, given that previous studies have found an association between this quantity and SMI. ${ }^{14,15}$

Leisure-time physical activity was assessed through three subjective questions. First, the respondents were asked "Have you participated in any sport and/or physical activity in the last three months?" The response options were: yes or no. Next, the frequency of activity was determined with the question: "How many days a week do you participate in sports or physical exercise?" Finally, the respondents were asked "In general, when you engage in sports and/or physical exercise, how many hours/minutes do you spend?" This questionnaire presented substantial agreement with the Global Physical Activity Questionnaire, especially the leisure domain (kappa coefficient: 0.70). ${ }^{16}$ We classified leisure-time physical activity as active or inactive with a cut-off of $150 \mathrm{~min} /$ week of activity. ${ }^{17}$

Tobacco use was evaluated through the question "Do you use any tobacco products?" The response options were "Yes, daily," "Yes, but not daily" and "No." We considered those who answered "Yes, daily" and "Yes, but not daily" as being exposed. The respondents were asked how many days per week they usually consumed alcohol, and at least 4 times per week was classified as high alcohol consumption. The respondents also reported the number of days per week they consumed sweets (e.g., cake, chocolate, candy, or cookies). We selected a cutoff point of seven days per week, considering that our aim was to screen for high consumption. A similar question was used to determine the consumption of soft drinks or artificial juice. Again, seven days per week was the cutoff point, considering that our aim was to screen for high consumption.

\section{Potential confounders}

Chronological age, as a continuous variable, was used as a covariate. Race was self-reported, dichotomized as white or non-white. Educational status was determined through the question: "What is your highest academic degree?" Three categories ( 1 = no academic degree; 2 = at least high school; and $3=$ at least college) were created as an indicator of socioeconomic status. Employment was assessed by asking whether the respondent had performed remunerated work in the last month, with the responses yes or no used as covariates.

\section{Statistics}

The sample was described using frequencies and $95 \%$ confidence intervals $(95 \% \mathrm{Cl})$. Logistic regression was used to analyze the association between each SMI and different lifestyle behaviors, adjusting for covariates (using the controls as a reference). All analyses were conducted in Stata 15.1.

\section{Ethics statement}

All procedures performed in the original studies involving human participants were approved by National Council of Ethics in Research (CONEP 10853812.7.0000.0008) in accordance with the ethical standards of the institutional and/or national research committee and with the 1964 Helsinki Declaration and its later amendments or comparable ethical standards. Informed consent was obtained from all participants.

All Brazilian National Health Survey data have been previously released in microdata sets (https://www.ibge. gov.br/estatisticas/sociais/saude/9160-pesquisa-nacionalde-saude.html?=\&t=microdados).

\section{Results}

The final sample consisted of 60,202 adults (25,920 men), with a mean age of $42.9(95 \% \mathrm{Cl} 42.7-43.2)$ years. The 
Table 1 Sample characteristics according to mental disorder

\begin{tabular}{|c|c|c|c|c|c|}
\hline & \multirow[b]{2}{*}{$\begin{array}{c}\text { General population } \\
(n=55,859)\end{array}$} & \multicolumn{3}{|c|}{ Mental illness } & \multirow[b]{2}{*}{$\begin{array}{l}\text { Mental multimorbidity } \\
\qquad(\mathrm{n}=241)\end{array}$} \\
\hline & & $\operatorname{MDD}(n=4,014)$ & $\begin{array}{l}\text { Bipolar disorder } \\
(\mathrm{n}=47)\end{array}$ & $\begin{array}{l}\text { Schizophrenia } \\
\quad(n=41)\end{array}$ & \\
\hline Sex (male) & $49.0(48.3-49.7)$ & $23.4(21.1-26.0)$ & $28.8(12.6-53.0)$ & $73.5(50.5-88.3)$ & $43.0(32.8-53.9)$ \\
\hline \multicolumn{6}{|l|}{ Age } \\
\hline $18-39$ & $48.9(48.2-49.7)$ & $32.1(29.7-34.7)$ & $36.8(17.2-62.0)$ & $17.4(6.6-38.4)$ & $52.7(42.1-63.1)$ \\
\hline $40-59$ & $33.4(32.7-34.1)$ & $44.8(42.1-47.4)$ & $58.2(33.0-79.7)$ & $62.4(39.5-80.8)$ & $36.2(27.1-46.4)$ \\
\hline $60+$ & $17.7(17.1-18.2)$ & $23.1(20.9-25.5)$ & $5.0(1.5-15.0)^{\prime}$ & $20.3(8.1-42.4)$ & $11.1(6.4-18.7)$ \\
\hline \multicolumn{6}{|l|}{ Educational status } \\
\hline No diplomas & $16.1(15.5-16.6)$ & $10.9(9.4-12.5)$ & $11.7(2.6-39.8)$ & $42.6(21.8-66.4)$ & $11.5(6.8-18.9)$ \\
\hline High school diploma & $70.1(69.4-70.8)$ & $72.5(70.1-74.7)$ & $52.2(26.1-77.1)$ & $57.2(33.5-78.1)$ & $69.0(57.2-78.8)$ \\
\hline Higher education diploma & $13.8(13.3-14.4)$ & $16.7(14.8-18.7)$ & $36.1(13.1-67.9)$ & $0.2(0.1-0.2)$ & $19.5(10.9-32.3)$ \\
\hline Employment status (yes) & 58.9 (58.2 to 59.7$)$ & $46.1(43.5-48.8)$ & $39.4(18.7-64.8)$ & $22.6(7.1-52.6)$ & $33.1(24.2-43.3)$ \\
\hline Race (white) & $53.2(52.5-53.9)$ & $55.2(52.5-57.8)$ & $31.9(14.0-57.4)$ & $42.2(21.4-66.2)$ & $66.0(56.0-74.6)$ \\
\hline Alcohol use ( $\geqslant 4$ days/week) & $3.8(3.5-4.1)$ & $2.9(2.0-4.0)$ & $5.0(1.0-20.8)$ & $12.7(1.8-54.3)$ & $2.6(0.9-7.5)$ \\
\hline Tobacco use & $14.4(13.9-14.9)$ & $18.4(16.4-20.5)$ & $12.9(5.6-26.9)$ & $29.2(11.8-56.1)$ & $22.8(15.8-31.8)$ \\
\hline TV viewing ( $\geqslant 5$ hours/day) & $8.3(7.9-8.7)$ & $11.7(10.1-13.6)$ & $4.6(1.2-16.1)$ & $32.0(12.5-60.7)$ & $16.6(10.3-25.5)$ \\
\hline Leisure PA (active) & $19.5(18.9-20.1)$ & $17.2(15.4-19.2)$ & $28.8(12.0-54.5)$ & $1.4(1.8-10.6)$ & $17.9(11.4-27.1)$ \\
\hline Sugary foods (7 days/week) & $15.1(14.6-15.7)$ & $18.6(16.6-20.9)$ & $27.2(6.9-65.2)$ & $25.8(9.3-54.3)$ & $26.3(17.5-37.6)$ \\
\hline Soft drinks ( 7 days/week) & $15.2(14.6-15.8)$ & $16.3(14.3-18.4)$ & $7.4(3.0-17.5)$ & $8.7(2.2-28.7)$ & $17.3(11.3-25.5)$ \\
\hline Cluster ( $\geqslant 2$ risk behaviors) & $20.0(19.4-20.7)$ & $23.6(21.4-26.0)$ & $12.4(5.2-26.5)$ & $32.6(13.0-61.0)$ & $27.7(19.7-37.5)$ \\
\hline
\end{tabular}

$\mathrm{MDD}=$ major depressive disorder; $\mathrm{PA}=$ physical activity .

Values are presented in weighted frequencies and $95 \%$ confidence intervals.

sample's mental illness characteristics (major depressive disorder $[n=4,014]$, bipolar disorder [ $n=47]$, schizophrenia $[n=41])$, mental multimorbidity, and the general population $(n=55,859)$ are presented in Table 1 . The proportion of men with clinical diagnoses of major depressive disorder was lower than the proportion of men in the whole sample, while employment status was lower among respondents with any mental condition than controls. Tobacco use, high TV viewing and consumption of sweets were lower among controls than those with SMls, except for tobacco use in the major depressive disorder group and TV viewing in the bipolar group.

The associations between mental disorders and lifestyle behaviors are presented in Table 2 . The adjusted models showed that the schizophrenia group was $92 \%$ (odds ratio [OR] 0.08 [95\% $\mathrm{Cl} 0.01-0.58]$ ) less likely to be active. Moreover, high TV viewing was more likely among respondents with major depressive disorder and schizophrenia. Respondents with major depressive disorder and mental multimorbidity had $37 \%$ and $90 \%$ higher odds of tobacco use, respectively. Similarly, major depressive disorder (34\%) and multimorbidity (83\%) were associated with higher odds of consumption of sweets. We found no significant associations between lifestyle behaviors and bipolar disorder.

\section{Discussion}

To our knowledge, this is the first Brazilian study to explore the unhealthy lifestyle of adults with SMI compared with the general population in a representative nationwide sample. Our main findings were that schizophrenia was associated with a lower physical activity level, major depressive disorder was associated with TV-viewing, tobacco use, and consumption of sugary foods and soft drinks, while bipolar disorder was not associated with any of the analyzed lifestyle behaviors.

Previous studies have observed that people with SMI are physically inactive and sedentary, ${ }^{7}$ smoke much more ${ }^{10}$ and have unhealthy dietary patterns. ${ }^{6}$ However, the present study extends the findings by focusing on a middle-income country. In general, our findings are in line (direction and magnitude) with those from high-income countries, as well as with previous findings from low- and middleincome countries. ${ }^{8}$

Our data demonstrate that major depressive disorder and mental multimorbidity were associated with higher rates of tobacco use and sugary food consumption. Both of these behaviors are associated with an acute release of dopamine ${ }^{18,19}$ which is suppressed in certain mental illnesses. ${ }^{20}$ Nicotine, specifically, can cause an acute reduction in hallucinations in schizophrenia patients. ${ }^{19,21}$ Schizophrenia is also associated with lower socialization, which can increase the likelihood of physical inactivity. ${ }^{22}$

Our findings reinforce the need to improve lifestyle behaviors among people with SMI. Recent research has suggested that interventions might be able to increase physical activity levels in people with $\mathrm{SMI},{ }^{23}$ and structured physical activity is recommended as an evidence-based treatment for this population to improve mental health, cognitive health and physical health outcomes. ${ }^{24}$ Previous research has also suggested that improvements in diet can reduce depressive symptoms ${ }^{25}$ and improve a range of physical health outcomes in people with SMI. ${ }^{26}$ Similarly, interventions to reduce smoking in people with SMI can result in improved physical and mental health. ${ }^{27,28}$ Given the aforementioned factors and the lifestyle behavior 


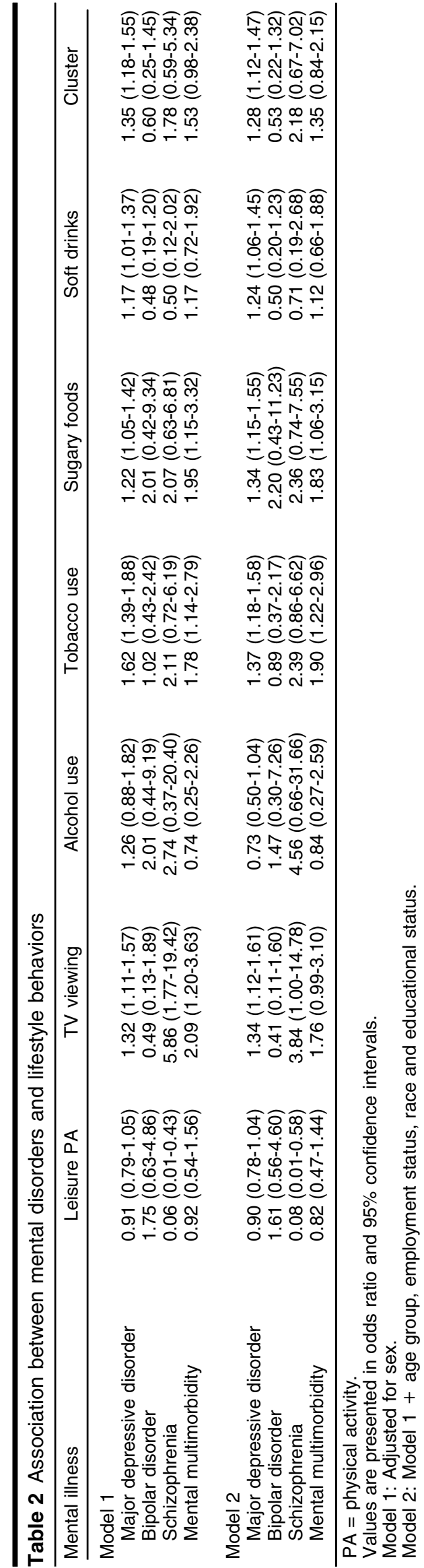

disparities we found in people with SMI, large-scale interventions are required to facilitate improvements in this population, since change is possible with adequate investment.

Our findings should be interpreted in light of some limitations. First, due to the cross-sectional design, we cannot draw any conclusions regarding causality. Second, we used subjective measures of lifestyle behaviors and clinical diagnoses. Third, the schizophrenia and bipolar groups were small, which reduced our statistical power and our ability to produce consistent estimates. Several previous studies have found that both schizophrenia and bipolar disorders are associated with health risk behaviors. ${ }^{6,7,9}$ Finally, information about other potential confounders, such as income, loneliness, and family history of mental illness, was unavailable. On the other hand, we presented data of different mental illnesses from a nationally representative sample of adults and found associations with lifestyle behaviors, which, to the best of our knowledge, is the first analysis of this kind among Brazilians.

In conclusion, among Brazilian adults, different SMls are associated with different unhealthy lifestyle behaviors. Our results reinforce the need for behavioral interventions for people with SMls.

\section{Acknowledgements}

We gratefully acknowledge the contributions of all participants in the present study, as well as the IBGE staff for data collection. This study received no specific grant from any funding agency in the public, commercial, or not-forprofit sectors. AOW receives funds from the Fundação de Amparo à Pesquisa do Estado de São Paulo (FAPESP; MSc degree scholarship process $2017 / 27234-2$ ). BS is supported by a Clinical Lectureship (ICA-CL-2017-03001) jointly funded by Health Education England (HEE) and the National Institute for Health Research (NIHR); he received funding from the NIHR Biomedical Research Centre at South London and the Maudsley NHS Foundation Trust. BS is also supported by the Maudsley Charity, King's College London and the NIHR South London Collaboration for Leadership in Applied Health Research and Care (CLAHRC). This paper presents independent research. The views expressed in this publication are those of the authors and not necessarily those of the acknowledged institutions.

\section{Disclosure}

The authors report no conflicts of interest.

\section{References}

1 Correll CU, Solmi M, Veronese N, Bortolato B, Rosson S, Santonastaso $P$, et al. Prevalence, incidence and mortality from cardiovascular disease in patients with pooled and specific severe mental illness: a large-scale meta-analysis of $3,211,768$ patients and 113,383,368 controls. World Psychiatry. 2017;16:163-80.

2 DE Hert M, Correll CU, Bobes J, Cetkovich-Bakmas M, Cohen D, Asai I, et al. Physical illness in patients with severe mental disorders. I. Prevalence, impact of medications and disparities in health care. World Psychiatry. 2011;10:52-77. 
3 GBD 2017 DALYs and HALE Collaborators. Global, regional, and national disability-adjusted life-years (DALYs) for 359 diseases and injuries and healthy life expectancy (HALE) for 195 countries and territories, 1990-2017: a systematic analysis for the Global Burden of Disease Study 2017. Lancet. 2018;392:1859-922.

4 De Hert M, Detraux J, Vancampfort D. The intriguing relationship between coronary heart disease and mental disorders. Dialogues Clin Neurosci. 2018;20:31-40.

5 Lawrence D, Hancock KJ, Kisely S. The gap in life expectancy from preventable physical illness in psychiatric patients in Western Australia: retrospective analysis of population based registers. BMJ. 2013;346:f2539.

6 Teasdale SB, Ward PB, Samaras K, Firth J, Stubbs B, Tripodi E, et al. Dietary intake of people with severe mental illness: systematic review and meta-analysis. Br J Psychiatry. 2019;214:251-9.

7 Vancampfort D, Firth J, Schuch FB, Rosenbaum S, Mugisha J, Hallgren $M$, et al. Sedentary behavior and physical activity levels in people with schizophrenia, bipolar disorder and major depressive disorder: a global systematic review and meta-analysis. World Psychiatry. 2017;16:308-15

8 Firth J, Siddiqi N, Koyanagi A, Siskind D, Rosenbaum S, Galletly C, et al. The Lancet Psychiatry Commission: a blueprint for protecting physical health in people with mental illness. Lancet Psychiatry. 2019;6:675-712.

9 Firth J, Stubbs B, Teasdale SB, Ward PB, Veronese N, Shivappa N, et al. Diet as a hot topic in psychiatry: a population-scale study of nutritional intake and inflammatory potential in severe mental illness. World Psychiatry. 2018;17:365-7.

10 Poirier MF, Canceil O, Bayle F, Millet B, Bourdel MC, Moatti C, et al. Prevalence of smoking in psychiatric patients. Prog Neuropsychopharmacol Biol Psychiatry. 2002;26:529-37.

11 Lund C, De Silva M, Plagerson S, Cooper S, Chisholm D, Das J, et al. Poverty and mental disorders: breaking the cycle in low-income and middle-income countries. Lancet. 2011;378:1502-14.

12 Pullar J, Allen L, Townsend N, Williams J, Foster C, Roberts N, et al. The impact of poverty reduction and development interventions on non-communicable diseases and their behavioural risk factors in low and lower-middle income countries: a systematic review. PLoS One. 2018;13:e0193378.

13 Instituto Brasileiro de Geografia e Estatística (IBGE). Pesquisa Nacional de Saúde 2013 [Internet]. [cited 2019 Oct 1]. www.pns.icict.fiocruz.br/.

14 Werneck AO, Oyeyemi AL, Szwarcwald CL, Vancampfort D, Silva DR. Associations between TV viewing and depressive symptoms among 60,202 Brazilian adults: the Brazilian national health survey J Affect Disord. 2018;236:23-30.

15 Sui X, Brown WJ, Lavie CJ, West DS, Pate RR, Payne JP, et al. Associations between television watching and car riding behaviors and development of depressive symptoms: a prospective study. Mayo Clin Proc. 2015;90:184-93.
16 Moreira AD, Claro RM, Felisbino-Mendes MS, Velasquez-Melendez G. Validity and reliability of a telephone survey of physical activity in Brazil. Rev Bras Epidemiol. 2017;20:136-46.

17 World Health Organization (WHO). Global recommendations on physical activity for health [Internet]. 2010 [cited 2019 Oct 1]. www. who.int/dietphysicalactivity/global-PA-recs-2010.pdf.

18 Avena NM, Rada P, Hoebel BG. Evidence for sugar addiction: behavioral and neurochemical effects of intermittent, excessive sugar intake. Neurosci Biobehav Rev. 2008;32:20-39.

19 Lucatch AM, Lowe DJ, Clark RC, Kozak K, George TP. Neurobiological determinants of tobacco smoking in schizophrenia. Front Psychiatry. 2018;9:672.

20 Belujon P, Grace AA. Dopamine system dysregulation in major depressive disorders. Int J Neuropsychopharmacol. 2017;20:1036-46.

21 Freeman TP, Stone JM, Orgaz B, Noronha LA, Minchin SL, Curran HV. Tobacco smoking in schizophrenia: investigating the role of incentive salience. Psychol Med. 2014;44:2189-97.

22 Soundy A, Freeman P, Stubbs B, Probst M, Vancampfort D. The value of social support to encourage people with schizophrenia to engage in physical activity: an international insight from specialist mental health physiotherapists. J Ment Health. 2014; 23:256-60.

23 Ashdown-Franks G, Williams J, Vancampfort D, Firth J, Schuch F, Hubbard K, et al. Is it possible for people with severe mental illness to sit less and move more? A systematic review of interventions to increase physical activity or reduce sedentary behaviour. Schizophr Res. 2018;202:3-16.

24 Stubbs B, Vancampfort D, Hallgren M, Firth J, Veronese N, Solmi M, et al. EPA guidance on physical activity as a treatment for severe mental illness: a meta-review of the evidence and Position Statement from the European Psychiatric Association (EPA), supported by the International Organization of Physical Therapists in Mental Health (IOPTMH). Eur Psychiatry. 2018;54:124-44.

25 Firth J, Marx W, Dash S, Carney R, Teasdale SB, Solmi M, et al. The effects of dietary improvement on symptoms of depression and anxiety: a meta-analysis of randomized controlled trials. Psychosom Med. 2019;81:265-80.

26 Teasdale SB, Ward PB, Rosenbaum S, Samaras K, Stubbs B. Solving a weighty problem: systematic review and meta-analysis of nutrition interventions in severe mental illness. $\mathrm{Br} J$ Psychiatry. 2017;210:110-8.

27 Stubbs B, Vancampfort D, Bobes J, De Hert M, Mitchell AJ. How can we promote smoking cessation in people with schizophrenia in practice? A clinical overview. Acta Psychiatr Scand. 2015;132: 122-30.

28 Gilbody S, Peckham E, Bailey D, Arundel C, Heron P, Crosland S, et al. Smoking cessation for people with severe mental illness (SClMITAR +): a pragmatic randomised controlled trial. Lancet Psychiatry. 2019;6:379-90. 